\title{
Cervical cancer: five-year survival and associated prognostic factors in the Western Province of Sri Lanka
}

\author{
PVSC Vithana $^{1 *}$, VP Bandarage ${ }^{2}$, DSAF Dheerasinghe ${ }^{2}$, S Perera $^{2}$, PN Samarakoon $^{2}$, HS Amaradasa $^{2}$, \\ SH Naseemdeen ${ }^{2}$ and E Fernando ${ }^{3}$ \\ ${ }^{1}$ Family Health Bureau of the Ministry of Health, 231, De Saram Place, Colombo 10. \\ ${ }^{2}$ National Cancer Control Program, 555, Elvitigala Mawatha, Colombo 05. \\ ${ }^{3}$ Ministry of Health, Ministry of Health, 385, Ven. Baddegama Wimalawansa Thero Mawatha, Colombo 10.
}

\begin{abstract}
Cervical cancer is the second commonest cancer among Sri Lankan females. Countrywide Pap smear screening programme was introduced in Sri Lanka in 1996. The present study determines the survival probabilities of cervical cancer patients diagnosed in 2008 in the Western Province of Sri Lanka and the associated prognostic factors. Details of the cervical cancer patients of the Western Province diagnosed in 2008 were obtained from hospital-based cancer registry. All 177 records were traced, and patients were followed up in the community to assess survival status at five years and associated prognostic factors. Observed survival rates at years one, three and five were calculated using Kaplan Meier product limit method. Covariates found to be potentially important prognostic variables with probability of 0.2 in log rank test were included in multivariate analysis using Cox proportional hazards model. Among 177 patients, mean \pm SD (in years) for age was $56.3 \pm$ 12.4 and $41(23.1 \%)$ had died within the five-year period. A majority $70(56.0 \%)$ were in stage III A and B. Overall one-, three- and five-year survival rates were $86 \%, 70.0 \%$ and 62.5 $\%$, respectively. District, clinical stage, and undergoing surgery were statistically significant factors in univariate analysis $(\mathrm{p}<$ $0.05)$. Only clinical stage was found to be significant in multiple Cox regression analysis $(\mathrm{p}<0.05)$. Women in stage III and IV were 3.5 times more likely to die compared to those in stage I and II at diagnosis. The study concludes that in Sri Lanka, five-year cervical cancer survival rate of $62.5 \%$ among patients is slightly higher in comparison to other developing countries. A majority have been diagnosed at III A or III B stages and strengthening of preventive strategies is recommended.
\end{abstract}

Keywords: Cervical cancer, clinical stage, five-year survival, survival analysis.

\section{INTRODUCTION}

Globally, cervical cancer is the fourth commonest cancer among females, and the seventh overall cause, with an estimated 528,000 new cases being diagnosed in 2012 (Ferlay et al., 2015). More than $85 \%$ of the global burden of cervical cancer occurs in developing countries accounting for $12 \%$ of all female cancers (Ferlay et al., 2015). Knowing the survival status of cancer patients and its prognostic factors are identified as very important steps in strengthening cancer prevention and control strategies. Yet, knowledge on country specific survival status of cervical cancer is quite inadequate.

EUROCARE-3 study identified European average five-year survival rate for cervical cancer as $62 \%$ (Coleman et al., 2003). U.S Surveillance, Epidemiology and End Results (SEER) expressed five-year survival rate for cervical cancer in United States (US) as $66.1 \%$ for the period 2005-2011 (National Cancer Institute US, 2019).

Shortage of publications on the survival of cancer patients in developing countries is much more challenging than in developed countries. Barriers in obtaining adequate follow-up information on the vital status of patients in developing countries has been identified as the underlying cause for this limitation (Sankaranarayanan et al., 1995).

\footnotetext{
* Corresponding author (chiranthikav@gmail.com; (iD https://orcid.org/0000-0002-0359-8058)
} 
'Cancer Survival in Low Middle Income Countries' published by the International Agency for Research on Cancer (IARC) in 2011 states that five-year agestandardised relative survival rate for cervical cancer cases diagnosed during 1990-2000 was highest in Seoul, South Korea with figures of 79-83 \%. India had 34-60\% of five-year age-standardised relative survival (Sankaranarayanan, 2011).

In the global context, age, ethnicity, religion, histopathological type, clinical stage and treatment methods were reported to be directly related to the survival status of cervical cancer patients (Sankaranarayanan et al., 1995; Loka et al., 2005; Pardo \& Cendales, 2009; Kumari et al., 2010; Muhamad et al., 2015).

In the Sri Lankan context, neoplasms were the second leading cause of death in 2012 (Ministry of Health Sri Lanka, 2015). Breast cancer was the commonest neoplasm and cervical cancer was the second commonest with an age-standardised incidence rate of 8.6 per 100,000 population among females in 2008 . It also accounted for the second highest percentage $(9.7 \%)$ of all female cancers (National Cancer Control Programme Sri Lanka, 2014). Age-standardised death rate due to cervical cancer among females was 1.2 per 100,000 population in 2006 (National Cancer Control Programme Sri Lanka, 2014).

National hospital-based cancer registry reports cancer surveillance data in Sri Lanka since 1985. Population based cancer registry in the district of Colombo was initiated in 2012. Mortality data comes from the Registrar General's Department. However, none of these sources still provide survival data. Hence, country specific data on cervical cancer survival and associated prognostic factors for Sri Lanka are not available (National Cancer Control Programme Sri Lanka, 2012; 2014).

Screening for cervical cancer using Pap smear test was introduced through Well Woman Clinics in Sri Lanka in 1996 (Family Health Bureau Sri Lanka, 2015). The programme targeted opportunistic screening for cervical cancer using Pap smear test while screening for breast cancer, hypertension and diabetic mellitus was carried out. Up to 2007, 35-60 year women were targeted for Pap smear screening. From 2008, coverage of 35-year age group has been prioritised for cervical screening (Family Health Bureau Sri Lanka, 2015). Pap smear test detects cervical cancer at pre-cancerous stage and timely intervention prevents the progression to cancer. However, participation for Pap smear testing was only $33.9 \%$ of the 35-year cohort of women in 2013 (Family Health Bureau Sri Lanka, 2015).
So far, no study has been conducted in Sri Lanka to assess the survival status and associated prognostic factors of cervical cancer. Hence, there are no country specific data on cervical cancer survival and associated prognostic factors for Sri Lanka (National Cancer Control Programme Sri Lanka, 2012; 2014). Knowing survival status of the cervical cancer patients is essential for decision making on strengthening preventive measures, for providing a quality care for cervical cancer survivors and filling the existing gaps in country-wide treatment and palliative care facilities. This paper reports the fiveyear survival and prognostic factors of cervical cancer patients diagnosed within 2008 in the Western Province of Sri Lanka.

\section{METHODOLOGY}

Adescriptive study of the cohort of cervical cancer patients diagnosed in 2008 in the Western Province of Sri Lanka was conducted to determine the survival probabilities and associated prognostic factors. Information of the cervical cancer patients diagnosed between 2008.01.01-2008.12.31 was obtained from national hospital-based cancer registry based on cancer patients attending the National Cancer Institute, Maharagama. Their clinic records were traced at the National Cancer Institute Maharagama (NCIM). Only 177 histologically confirmed patients with cervical cancer were included in the study. Total of 177 were included in the analysis. Data on age at diagnosis, incidence date, clinical stage categorised according to the Federation of Gynaecology and obstetrics (FIGO) classification, histology, treatment, last contact date at the hospital and survival status on that day were abstracted from clinic folders using designed data extraction form for the study. Their survival was determined after tracing them in the community using data extraction form two. The data on survival status and in case of deaths, date of death, place of death, death certificate number and cause of death were extracted. An interviewer-administrated questionnaire was used to assess socio-demographic prognostic factors and the survival in the community.

The patient data extraction forms and questionnaire were pre-tested among 25 cervical cancer patients residing outside Western Province reported as incident cases in hospital-based cancer registry in 2008. Necessary modifications on sequencing, timing and comprehensiveness of the questionnaire were performed. Hospital-based data collection at NCIM was conducted by medical officers and data collection in the community was conducted by public health nursing sisters who were conversant on conducting interviews. Patients' homes 
were visited. Identity and survival status of the patient were ascertained. Informed written consent was taken from the patient or next of kin before administrating the questionnaire. In case the patient has already died, details of the date and cause of death were ascertained by referring to death registration documents. Testretest reliability for field component was tested by reinterviewing a random sample of 20 respondents in the community by an investigator. For data abstraction component, test-retest reliability was measured by a reabstraction of data from 25 clinic records already used in data collection by the investigator. At every stage of the study, specific measures were taken to ensure validity and reliability of data.

Ethical clearance was from the Ethical Review Committee of Faculty of Medicine, University of Colombo. Permission of the directors of NCIM, National Cancer Control Programme and regional directors of health services was obtained prior to the commencement of the study.

Data were entered into Microsoft Excel. Entire data processing and analysis were conducted using STATA 12 statistical software. Descriptive statistics were presented using percentages, mean and standard deviations. Observed survival rates were calculated by Kaplan Meier product limit method. Survival time was limited only for the five years from the incidence date. Survival at year 1, 3 and 5 were calculated. Log-rank test was used in univariate analysis to identify potentially important prognostic variables. Cox proportional hazards model was used in multivariate analysis using covariates found to have a probability of 0.2 and below in log rank test. For each variable included in the Cox models, the assumption of proportional hazards was checked by using log (-log survival) plot. No violations of assumption were found as plotted lines were roughly parallel over time.

\section{RESULTS AND DISCUSSION}

\section{Results}

For survival analysis, only 177 of the eligible patients were included. Interrater test retest reliability measured using Kappa of the hospital-based data collection was 0.84 and 0.76 for field-based data collection. Both showed excellent agreement of over 0.75 (Abramson \& Abramson, 1999). Thus, the reliability of the study instruments was considered satisfactory.

Out of 177, $41(23.1 \%)$ had experienced death within the five-year period from the incidence date. A majority, $79(44.6 \%)$ were from Colombo district. Sixty-one
(34.5\%) and thirty-seven (20.9\%) were from Gampaha and Kalutata Districts, respectively. Mean age was 56.3 years with a standard deviation of 12.4 years. Hundred and fifteen $(65.0 \%)$ were over 50 years. Out of 177 , $107(60.5 \%)$ were squamous cell carcinoma while 43 $(24.3 \%)$ were recorded just as malignant. Twenty-seven (15.3\%) did not have histological diagnosis recorded. A majority $(\mathrm{n}=70 ; 56.0 \%)$ were in stage III A and $\mathrm{B}$, while $28.8 \%(n=36)$ were in stage II A and B. Only $13(10.4 \%)$ were in stage I A and 6(4.8\%) were in IV A and B. About one third, $42(31.8 \%)$ had received radiotherapy as first line of treatment while $24(18.2 \%)$ had chemo-radiation. Only $17(12.9 \%)$ had chemotherapy as the first treatment method while $17(12.9 \%)$ had undergone surgery as first option. Thirty-four $(24.2 \%)$ had other options as first line. Sixty-six $(40.2 \%)$ had undergone surgery at some point. Among them, $30(75.0 \%)$ had undergone total abdominal hysterectomy. Nine $(22.5 \%)$ and one $(2.5 \%)$ had undergone Wertheim's hysterectomy and laparotomy, respectively. Hundred and twenty-two (75.8\%) had undergone radiotherapy at some stage while 86 (53.4\%) had gone through chemotherapy (Table 1).

Socio-demographic data were available only for $63(36 \%)$ of the group. The majority $54(85.7 \%)$ were Sinhalese and 44 (69.8\%) were Buddhists. Fifty (79.4\%) were not employed. Only 13 (20.6\%) were employed. Fifty-one $(80.9 \%)$ had education level above grade five, while $28(44.4 \%)$ had education above grade nine. A majority, 54 (87.1\%) were married. Thirty-one (57.4\%) were having family income over Rs. 10,000. Overall, one-, three- and five-year survivals were $86 \%$ (95\% CI: 80-92\%), 70\% (95\% CI: 61-79\%) and 62.5\% (95\% CI: $53-72 \%$ ) respectively (Figure 1 ).

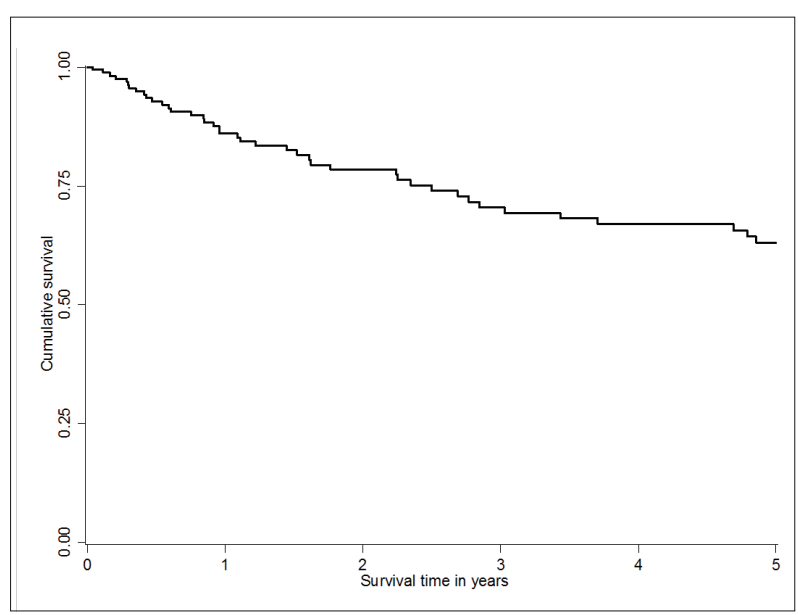

Figure 1: Observed survival among cervical cancer patients in Western Province Sri Lanka 
Table 1: Association between selected socio-demographic and patient management related factors with survival among cervical cancer patients in Western Province Sri Lanka

\begin{tabular}{|c|c|c|c|c|}
\hline Factor & $\begin{array}{l}\text { Number in the } \\
\text { study sample (\%) }\end{array}$ & $\begin{array}{l}\text { Observed deaths } \\
\text { within five years }\end{array}$ & $\begin{array}{l}\text { Expected deaths for } \\
\text { five-year period in } \\
\text { applying log rank test }\end{array}$ & $\begin{array}{l}\text { Significance } \\
\text { (log rank test) }\end{array}$ \\
\hline \multicolumn{5}{|l|}{ District $(\mathrm{n}=177)$} \\
\hline Colombo & $79(44.6)$ & 18 & 17 & $\mathrm{p}=0.02$ \\
\hline Gampaha & $61(34.5)$ & 21 & 15 & \\
\hline Kalutara & $37(20.9)$ & 2 & 9 & \\
\hline \multicolumn{5}{|c|}{$\begin{array}{l}\text { Age }(\mathrm{n}=177) \text { Mean age } \\
=56.34 \text { years }\left(\mathrm{SD}^{*}=12.40\right)\end{array}$} \\
\hline 50 years and below & $62(35.0)$ & 14 & 16 & $\mathrm{p}=0.47$ \\
\hline$>50$ years & $115(65.0)$ & 27 & 25 & \\
\hline \multicolumn{5}{|l|}{ Ethnicity $(\mathrm{n}=63)$} \\
\hline Sinhala & $54(85.7)$ & 25 & 26 & $\mathrm{p}=0.59$ \\
\hline Other & $8(14.3)$ & 5 & 4 & \\
\hline \multicolumn{5}{|l|}{ Religion $(\mathrm{n}=63)$} \\
\hline Buddhist & $44(69.8)$ & 18 & 22 & $\mathrm{p}=0.09$ \\
\hline Other & $19(30.2)$ & 12 & 8 & \\
\hline \multicolumn{5}{|l|}{ Stage $(\text { FIGO })^{* *}(\mathrm{n}=125)$} \\
\hline I A,II A \&II B & $49(39.2)$ & 9 & 16 & $\mathrm{p}=0.04$ \\
\hline III A,III B, IVA and IV B & $76(60.8)$ & 20 & 13 & \\
\hline \multicolumn{5}{|l|}{ First treatment $(n=132)$} \\
\hline Surgery & $17(12.9)$ & 3 & 5 & $\mathrm{p}=0.12$ \\
\hline Chemotherapy & $17(12.9)$ & 5 & 4 & \\
\hline Radiotherapy & $42(31.8)$ & 12 & 9 & \\
\hline Chemo radiation & $24(18.2)$ & 8 & 5 & \\
\hline Other & $32(24.2)$ & 3 & 8 & \\
\hline \multicolumn{5}{|l|}{ Whether undergone } \\
\hline \multicolumn{5}{|l|}{ Surgery $(n=164)$} \\
\hline Yes & $66(40.2)$ & 7 & 16 & $\mathrm{p}=0.002$ \\
\hline No & $98(59.8)$ & 27 & 18 & \\
\hline \multicolumn{5}{|l|}{ Whether undergone } \\
\hline \multicolumn{5}{|l|}{ Radiotherapy $(\mathrm{n}=161)$} \\
\hline Yes & $122(75.8)$ & 26 & 27 & $\mathrm{p}=0.68$ \\
\hline No & $39(24.2)$ & 8 & 7 & \\
\hline \multicolumn{5}{|l|}{ Whether undergone } \\
\hline \multicolumn{5}{|l|}{ Chemotherapy $(\mathrm{n}=161)$} \\
\hline Yes & $86(53.4)$ & 23 & 19 & $\mathrm{p}=0.18$ \\
\hline No & $75(46.6)$ & 10 & 14 & \\
\hline \multicolumn{5}{|l|}{ Type of the surgery $(n=40)$} \\
\hline TAH \&BSO $* * *$ & $30(75.0)$ & 4 & 3 & $\mathrm{p}=0.55$ \\
\hline Wertheim's hysterectomy & $9(22.5)$ & 0 & 1 & \\
\hline Laparotomy & $1(2.5)$ & 0 & 0 & \\
\hline
\end{tabular}

*Standard deviation, ${ }^{* *}$ Classification of International Federation of Gynecology and Obstetrics,

***Trans-abdominal hysterectomy with bilateral salpingo-oophorectomy 
In univariate analysis, significant differences in the survival rates were observed with district, clinical stage and whether undergone surgery at a probability of $\mathrm{p}<0.05$ (Table1). Histopathological type was not included in this univariate analysis or multivariate analysis as only $60.5 \%$ $(n=107)$ of the patient clinic records had information on histopathological diagnosis. All of these 107 patients were recorded as having squamous cell carcinoma, while other $39.5 \%$ were lacking any histological diagnosis.

District, clinical stage, first treatment, whether undergone surgery, whether undergone chemotherapy and religion were included in the Cox proportional hazard model as they had a probability of 0.2 or below. Survival differences of significant level below 0.05 were shown by clinical stage and religion. Thus, only clinical stage and religion were included in the final model. Those who were in clinical stage I and II had better survival than those in stage III and 1V (Figure 2). Buddhists had a better survival than others. According to multiple Cox regression model, women in stage III and IV were 3.5 times more likely to die compared to those in stage I \& II at diagnosis. (Table 2). Religion was not taken as significant as confidence interval (CI) of hazard ratio included 1 despite the $p$ value of $<0.05$ (Table 2 ).

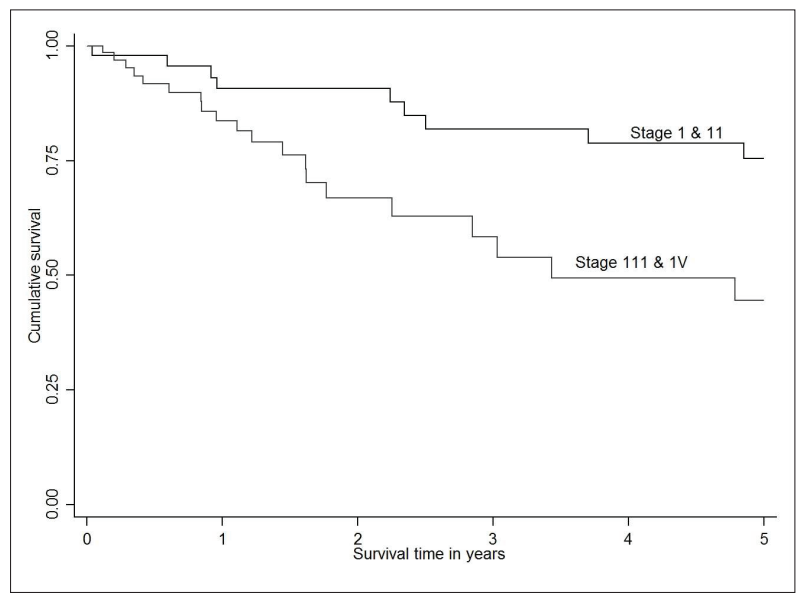

Figure 2: Observed survival by clinical stage among cervical cancer patients in Western Province Sri Lanka

Table 2: Hazard ratio and associated factors for cervical cancer survival in the Western Province of Sri Lanka

\begin{tabular}{lcccc}
\hline Variable & $\begin{array}{c}\text { Regression } \\
\text { coefficient (b) }\end{array}$ & $\begin{array}{c}\text { Hazard ratio } \\
\text { (HR) }\end{array}$ & 95\% CI of HR & $\begin{array}{c}\text { Significance } \\
\text { p value }\end{array}$ \\
\hline Clinical stage & & & & 0.01 \\
Stage I \& II & 0 & 1 & & \\
Stage III \& IV & 1.26 & 3.53 & $1.32-9.46$ & 0.05 \\
Religion & & & & \\
Buddhist & 0 & 1 & & \\
Other & 0.91 & 2.47 & $0.98-6.24$ & \\
\hline
\end{tabular}

CI - Confidence interval

\section{Discussion}

Forty-one had experienced death within the five-year period from the incidence date among 177 cervical cancer patients diagnosed in 2008. Overall, one-, threeand five-year survivals were $86 \%$ (95\% CI: 80-92\%), $70.0 \%$ (95\% CI: 61-79\%) and 62.5\% (95\% CI: 53-72\%) respectively. District, clinical stage and whether patient has undergone surgery, were found to be significant prognostic factors in univariate analysis at $\mathrm{p}<0.05$. Only clinical stage was found to be a significant prognostic factor in multiple Cox regression analysis. According to multiple Cox regression analysis women in stage III and IV were 3.5 times more likely to die compared to those in stage I and II at diagnosis.
In global context, European average of five-year survival of cervical cancer assessed in EUROCARE-3 study was $62 \%$ (Coleman et al., 2003). In U.S Surveillance, Epidemiology and End Results (SEER) for 2010-2016, it was $66.1 \%$ (National Cancer Institute US, 2019). This shows that the Sri Lankan figure of five-year survival of cervical cancer $(62.5 \%)$ reported in the present study was comparable with developed countries though Sri Lanka is a developing country. However, Japan has shown better five-year survival of 70.2 \% during 1975-1996 in a study conducted using the reported data of 8966 cervical cancer cases, newly diagnosed in 1975-1996 from the Osaka Cancer Registry's database in Japan (Loka et al., 2005). 
In comparison with the findings of the second IARC volume on Cancer Survival in low middle income countries published in 2011 with data of 27 populationbased cancer registries from 14 countries, Sri Lankan five-year survival of cervical cancer elicited in the present study $(62.5 \%)$ seems to be better. There, fiveyear age-standardised relative survival for cervical cancer cases diagnosed during 1990-2000 was highest in Seoul, South Korea with 79-83 \%, while India had 34-60\% of five-year age-standardised relative survival (Sankaranarayanan, 2011). However, as the present study was based on the findings of hospital-based cancer registry, the comparability between two studies is limited. The Sri Lankan figure is comparable with the figure of five-year survival rate reported for 376 women diagnosed with cervical cancer over 1964-1988, in Reykjavik, which was 63 \% (Sigurdsson et al., 1991)

The Sri Lankan figure is much higher than the fiveyear observed survival rate of $47.4 \%$ found among 452 cervical cancer patients registered during 1984 by the hospital registry of the Regional Cancer Centre, Trivandrum, Kerala, India (Sankaranarayanan et al., 1995). Yet, it is lower than the figure of $83.3 \%$ which was found in a retrospective study conducted among 552 cervical cancer patients treated in Lions Cancer Hospital, Visakhapatnam Andhra Pradesh, India between January 2001 to December 2003 (Kumari et al., 2010). India being a large country, cervical cancer survival differs from state to state depending on the availability of cancer treatment and palliative care facilities.

It is less than the five-year survival of $71.1 \%$ shown in a study conducted in Malaysia using data of 5,859 cervical cancer patients diagnosed with cervical cancer during 2000-2005 period where cancer treatment and palliative care seems to be more advanced than in Sri Lanka (Muhamad et al., 2015). There, log-rank test finding also showed that there were significant differences in the five-year survival rate among different ethnic groups.

In global literature, survival of cervical cancer patients is found to be directly related to certain factors such as stage, histopathology, age, ethnicity, religion and treatment options (Sankaranarayanan et al., 1995; Loka et al., 2005; Pardo \& Cendales 2009; Kumari et al., 2010; Muhamad et al., 2015). However, in this study, only clinical stage was found to be a significant prognostic factor. Women in stages III and IV were 3.5 times more likely to die compared to those in stage I and II at diagnosis. In the present study histopathology was not compared with survival as out of 177 , all 107
(60.5\%) having histopathological diagnosis were recorded as squamous cell carcinoma while 43 (24.3\%) were recorded as just being malignant. Twenty-seven $(15.3 \%)$ records did not have any histopathological diagnosis recorded. This was a limitation which could not be overcome as secondary data were used in this study. Further, this reflects the importance of strengthening recording important details in clinic records. Training of medical staff on these aspects should be strengthened.

In spite of having fairly good five-year survival, a majority 76 (60.8 \%) were in stage III A and B. Improved treatment strategies, availability of free health services and good patient follow-up may have contributed for having a fairly good five-year survival. However, case detection at late stages reflects the need of strengthening screening programme and this paper suggests revisiting and strengthening the primary preventive and screening strategies in an intensified manner.

Present study was conducted in the province with the highest population in the country, and as it is not a nationwide study, findings cannot be generalised to the entire country. All possible measures were employed to contact patients in the field. However, due to lack of accuracy of the addresses in the field only 63 of them were contacted at their homes. This highlights the need of training hospital staff and the community on the importance of correct recording of patient details. However, most of the survival period records of others were obtained from the clinic folders as Sri Lanka is providing a good healthcare follow-up at the hospital.

Although patient details were obtained from the best available source of data - hospital-based national cancer registry - it lacks the data of the patients taking treatment in private sector and abroad. This resulted in a certain underestimation of the number of cervical cancer patients diagnosed in the Western Province.

Future studies by incorporation of details of other factors that could be associated with the survival assessment, parallel to the expansion of the populationbased cancer registry is needed to get a broader perspective on the five-year survival rate and associated factors.

\section{CONCLUSION}

Five-year survival of cervical cancer in Sri Lanka is $62.5 \%$. This figure is closer to the survival rates in developed countries rather than developing countries. 
The clinical stage was associated with survival. Despite having a good survival rate, a majority of cervical cancers were diagnosed at stage III A and III B. This may reflect that good survival is related to timely treatment rather than due to the achievements in the screening or primary prevention. Therefore, there is urgency for strengthening cervical cancer screening programme within the country targeting detection at a pre-cancerous stage or at a very early stage and timely referrals for interventions while taking all other primary prevention strategies.

\section{REFERENCES}

Abramson J.H. \& Abramson Z.H. (1999). Survey Methods in Community Medicine: Epidemiological Research, Programme Evaluation, Clinical Trials. $5^{\text {th }}$ edition, pp. 181-182. Churchill Livingstone, Edinburgh, UK.

Coleman M.P., Gatta G., Verdecchia A., Estève J., Sant M., Storm H., Allemani C., Ciccolallo L., Santaquilani M. \& Berrino F. (2003). EUROCARE-3 summary: cancer survival in Europe at the end of the $20^{\text {th }}$ century. Annals of Oncology : Official Journal of the European Society for Medical Oncology 14 (Suppl 5): 128-149.

DOI: https://doi.org/10.1093/annonc/mdg756

Family Health Bureau Sri Lanka (2015). Annual Report of Family Health 2013. Family Health Bureau, Colombo, Sri Lanka.

Ferlay J., Soerjomataram I., Dikshit R., Eser S., Mathers C., Rebelo M., Parkin D.M., Forman D. \& Bray F. (2015) Cancer incidence and mortality worldwide: Sources, methods and major patterns in GLOBOCAN 2012. International Journal of Cancer 136(5): E359-E386. DOI: https://doi.org/10.1002/ijc.29210

Kumari K.G., Sudhakar G., Ramesh M., Kalpana V.L. \& Paddaiah G. (2010). Prognostic factors in cervical cancer: a hospital-based retrospective study from Visakhapatnam City, Andhra Pradesh. Journal of Life Sciences 2(2): 99-105. DOI: https://doi.org/10.1080/09751270.2010.11885159

Loka A., Tsukuma H., Ajiki W. \& Oshima A. (2005). Influence of age on cervical cancer survival in Japan. Japanese Journal of Clinical Oncology 35(8): 464-469.

DOI: https://doi.org/10.1093/jjco/hyi125

Ministry of Health SriLanka (2015). Annual Health Bulletin 2012. Ministry of Health, Colombo, Sri Lanka.

Muhamad N.A., Kamaluddin M.A., Adon M.Y., Noh M.A., Bakhtiar M.F., Ibrahim T.N.S., Mahmud S.H. \& Aris T. (2015). Survival rates of cervical cancer patients in Malaysia. Asian Pacific Journal of Cancer Prevention 16(7): $3067-$ 3072.

DOI: https://doi.org/10.7314/apjcp.2015.16.7.3067

National Cancer Control Programme Sri Lanka (2012). Commencement of Population Based Cancer Regigstry in the Colombo District. Sri Lanka. National Cancer Control Programme,Colombo, Sri Lanka.

National Cancer Control Programme Sri Lanka (2014). Cancer Incidence Data: Sri Lanka 2008. Sri Lanka. National Cancer Control Programme, Colombo, Sri Lanka.

National Cancer Institute US (2019). Surveillance, Epidemiology, End Results Programme, Cervical CancerCancer Stat Facts. Available at https://seer.cancer.gov/ statfacts/html/cervix.html, Accessed 11 July 2020.

Sankaranarayanan R. (2011). Cancer survival in Africa, Asia, the Caribbean and Central America. Introduction. IARC Scientific Publications 2011(162): 1-5.

Sankaranarayanan R., Krishnan N., Jayaprakash P.G., Stanley P.G., Varghese C., Ramadas V,. Padmakumary G. \& Padmanabhan T.K. (1995). Cervical cancer in Kerala: A hospital registry-based study on survival and prognostic factors. British Journal of Cancer 72(4): 1039-1042. DOI: https://doi.org/10.1038/bjc.1995.458

Pardo C. \& Cendales R. (2009). Survival analysis of cervical cancer patients. Biomedica 29(3): 437-447.

DOI: https://doi.org/10.7705/biomedica.v29i3.2

Sigurdsson K., Hrafnkelsson J., Geirsson G., Gudmundsson J. \& Salvarsdóttir A. (1991) Screening as a prognostic factor in cervical cancer: analysis of survival and prognostic factors based on Icelandic population data, 1964-1988. Gynecologic Oncology 43(1): 64-70.

DOI: https://doi.org/10.1016/0090-8258(91)90011-s 